\title{
The Syntax-Semantics Interface of Resultative Constructions in Mandarin Chinese and Cantonese
}

\author{
Pui Lun Chow \\ Department of Linguistics, University of Hong Kong, \\ MB126, Main Building, The University of Hong Kong, Hong Kong (852), China \\ h08dezi@hku.hk
}

\begin{abstract}
The mapping between grammatical functions and thematic roles of resultative constructions has been widely discussed in different frameworks of syntax, and theories have been proposed to account for the mismatches between them. The question behind the construction of these mapping theories always lies in the choice of suppressing one of the two competing roles or fusing them in order to maintain the Consistency Principle or Uniqueness Condition. However, these mechanisms always involve ad hoc additional mapping rules which need further justification or they may not be applicable to other mapping phenomena. In this paper, I am going to analyze the mapping phenomenon of resultative constructions in Mandarin Chinese and Cantonese by drawing insights from conceptual semantics (Jackendoff, 1990). I will show how conceptual structures can capture the special properties of resultative constructions and handle the mapping phenomenon mentioned above naturally.
\end{abstract}

Keywords: resultative constructions, mapping, conceptual semantics structure, verb-copying constructions, syntactic-semantic interface

\section{Section 1 Introduction}

The grammatical functions and thematic roles mapping phenomenon of resultative constructions has been widely discussed in different frameworks of syntax and mapping theories have been proposed to account for the mismatches between grammatical functions and thematic roles (the Causative Hierarchy account (Li 1995); Lexical Mapping Theory ((Levin 1986) and (Bresnan and Zaenen 1990)); Event Structure Account (Alsina 1992), etc.). The question behind the construction of these mapping theories always lies in the choice of suppressing one of the two competing roles or fusing two component roles in order to maintain the Consistency Principle or Uniqueness Condition, which says a particular attribute in a functional structure must have one and only one value (Dalrymple, 2001). However, the mechanisms of suppressing one of the competing roles or fusing two component roles always involve ad hoc additional mapping rules which need further justification or they may not be applicable to other mapping phenomena. 
In this paper, I am going to show how the semantics of resultative constructions in Mandarin Chinese and Cantonese can be linked to the syntax by drawing insights from conceptual semantics (Jackendoff, 1990). Along with a demonstration of the application of conceptual structures in accounting for the mapping phenomenon in Mandarin Chinese and Cantonese resultative constructions, the paper will focus on the strange or marked mapping phenomenon of a Mandarin Chinese sentence discussed in Her’s (2006) paper, “張三 追-累-了 李四 Zhāngsān zhuī-lèi-le Lìs̀̀" (John chase-tired-ASP Lee) ${ }^{1}$. I will also show in this paper how the representation of conceptual structures can capture the special properties of resultative constructions and at the same time handle the relevant mapping phenomena, including that of the marked structure mentioned above, naturally.

\section{Section 2 The Conceptual Semantics Approach}

To handle the argument-function mapping of possible ambiguous interpretations of resultative constructions like the sentence above in Mandarin and Cantonese, an approach considering the conceptual semantics as proposed by Jackendoff (1990) seems suitable. Unlike Lexical Mapping Theory ((Levin 1986) and (Bresnan and Zaenen 1990)), which handles mapping by assigning intrinsic values to individual roles and grammatical functions, the conceptual semantics approach handles mapping by looking at the conceptual structure of the sentence as a whole. Thus, each interpretation of the sentence would possess its corresponding conceptual structure. The mapping is done according to the position each participant of the event denoted by the sentence is put.

One of the features of Mandarin and Cantonese resultative constructions is that the resulting predicate or the means verb, which is usually adjective-like in a resultative compound contributes to the core meaning of the sentence unlike modifying adjuncts, which only provide additional information. These adjuncts are called "Superordinate Adjuncts" (Jackendoff, 1990). According to Jackendoff's (1990) analysis, resultative sentences like:

(1-i) Peter swung the towel dry.

(2-i) The gardener watered the tulips flat.

(3-i) The man hit the dog dead.

can be rephrased as follows:

(1-ii) Peter made the towel dry by watering it.

(2-ii) The gardener made the tulips flat by watering them.

(3-ii) The man made the dog dead by hitting it.

\footnotetext{
${ }^{1}$ According to Her (2006), there are three acceptable interpretations for this sentence. Interpretation 1: John chased Lee to the extent of making him (Lee) tired. Interpretation 2 : John chased Lee and (John) got tired. Interpretation 3 : Lee chased John and was made tired (by John). Further discussion on the above interpretations will be done in Section 4.
} 
Now that sentences (1-i), (2-i) and (3-i) are rephrased, with the superordinate adjuncts denoted by the 'by' phrases at the end. Jackendoff (1990) suggests that the rephrased constructions are more basic for formulation. We will take the first sentence as an example. The conceptual structure of the sentence is as follows,

(4) The conceptual structure of (1-i):

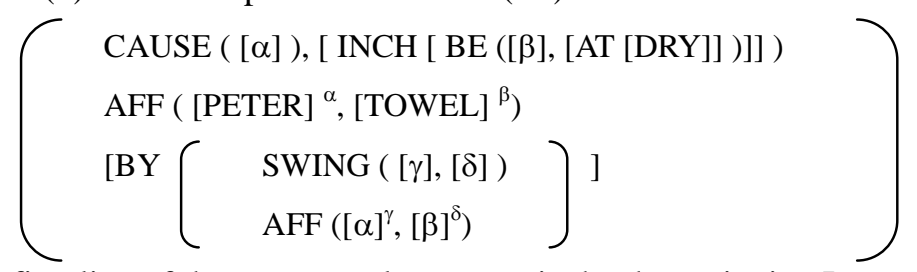

The first line of the conceptual structure is the thematic tier. It says that an individual $[\alpha]$ causes (i.e. CAUSE) an internal change (i.e. INCH) to another individual $[\beta]$ to be in a state of being dry (i.e. BE ... [AT ["DRY"]]). The second line is the action tier which tells that the two participants (i.e. the actor $[\alpha]$ and the patient $[\beta]$ ) are "PETER" and "TOWL" respectively. The superordinate adjunct BY part states that the above action is caused by a swinging action (i.e. SWING) with two participants, i.e. $[\gamma]$ and $[\delta]$. $[\alpha]$ takes the first position in the action tier within the BY subpart, which states that "PETER", which is co-indexed with $[\alpha]$, is the actor; whereas $[\beta]$ takes the second position in the action tier within the BY subpart, which states that "TOWEL", which is co-indexed with $[\beta]$, is the patient.

In the above structure, the resultant is introduced by the conceptual function "BY". One important point is that the subpart "BY" is not adjunctive. This representation echoes with the property of predicates or complex predicates in resultant constructions that neither of the predicates is adjunctive to each other.

\section{Section 3 Mapping of Mandarin and Cantonese Resultatives}

Having demonstrated the representation of resultative constructions in the case of English, we are in a better position to engage in the analysis of Mandarin Chinese and Cantonese RVCs. We will look at three types of resultative sentences in each language.

The first type is the most unmarked case of resultative construction.

Example sentence in Mandarin Chinese:

(5) 這個男人打- 死了那條狗。

zhè gè nán rén dă-š̌ le nà tiáo gŏu

This CL man hit-dead ASP that CL dog.

"This man hit the dog and made it dead."

Example sentence in Cantonese:

(6) 呢個男人打死左㧽隻狗。

nei4 go3 naam4 jan4 daa2-sei2 zo2 gwo2 zek3 gau2

This CL man hit-dead ASP that CL dog.

"This man hit the dog and made it dead." 
The sentences in Mandarin and Cantonese have the same syntactic structure and can be represented in the conceptual structures below.

(7) Conceptual structure of (5):

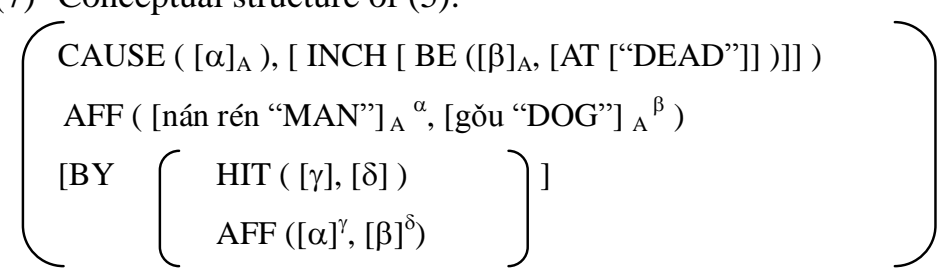

The Argument-marked (or A-marked) arguments in the above structure are ordered as [nán rén "MAN"] and [gǒu "DOG"] according to the thematic hierarchy ${ }^{2}$. The argument in the first position is the ACTOR while the second argument is the PATIENT. The first A-marked argument is linked to the external argument or the subject, whereas the second argument is linked to the object.

(8) Conceptual structure of (6):

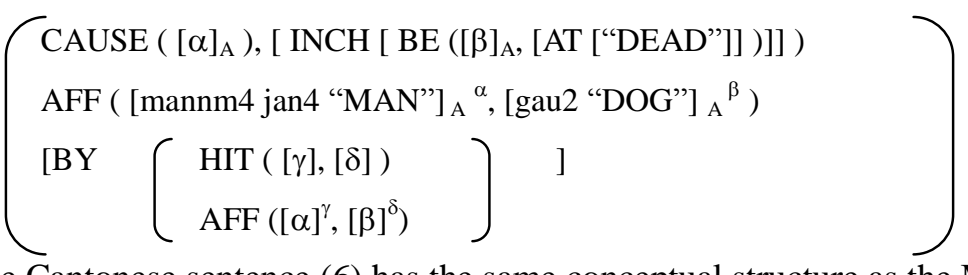

Since the Cantonese sentence (6) has the same conceptual structure as the Mandarin Chinese sentence (5), the mapping from semantics to syntax is the same.

The second type involves inversion ${ }^{3}$ in resultative constructions. Consider the sentence in Mandarin Chinese:

(9) 這種藥會吃-死 你。 zhè zhǒng yào huì chī-š̃ nĭ

This CL medicine will eat-dead you.

"Eating this medicine will kill you."

(10) Conceptual structure of (9):

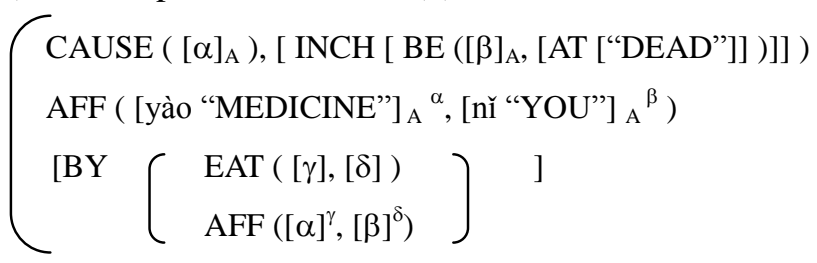

The first line of the semantic structure above (i.e. the thematic tier) is basically the same as the thematic tiers in the conceptual structures for sentences (5) and (6). The second line is the action

\footnotetext{
${ }^{2}$ According to Jackendoff (1990:258), the thematic hierarchy is an order of "the A-marked arguments in the action tier from left to right, followed by the A-marked arguments in the main conceptual clause of the thematic tier, from least embedded to most deeply embedded". The ordered A-marked arguments can be listed as Actor $>$ Patient $\left(\mathrm{AFF}^{-}\right)$or Beneficiary $\left(\mathrm{AFF}^{+}\right)>$Theme $>$Location, Source, Goal.

3 The canonical linking maps the Actor, or EATER, to the subject, and the Patient, or the EATEE, to the object. However, (9) shows an inverse mapping in which the Actor is mapped to the surface object instead of the subject.
} 
tier which states that the two participants (i.e. the actor $[\alpha]$ and the patient $[\beta]$ ) are "yào MEDICINE" and "nǏ YOU" respectively. The superordinate adjunct BY part states that the result is caused by an eating action (i.e. EAT) with two participants, i.e. $[\gamma]$ and $[\delta]$. $[\alpha]$ takes the first position in the action tier within the BY subpart, which states that "nI YOU", which is co-indexed with $[\alpha]$, is the actor; whereas $[\beta]$ takes the second position in the action tier within the BY subpart, which states that "yào MEDICINE", which is co-indexed with [ $\beta]$, is the patient. Consider the sentence in Cantonese:

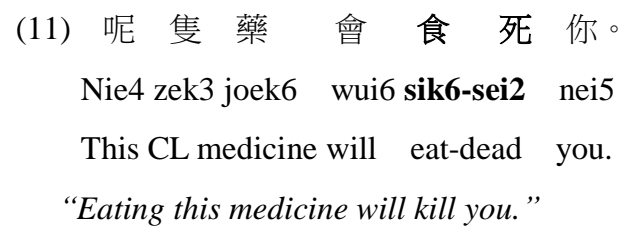

(12) Conceptual structure of (11):

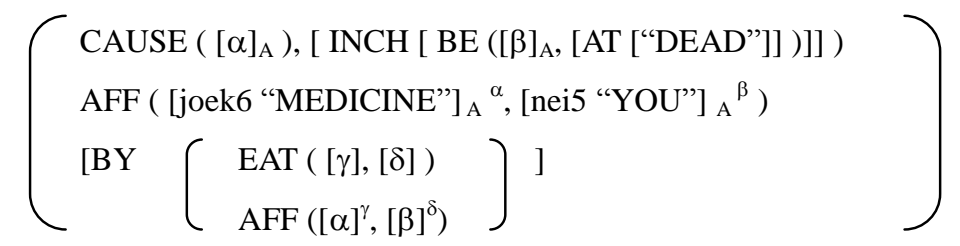

Again, the resultative sentences in both languages have the same conceptual semantic structure. In these two cases, joek6 "MEDICINE" is put in the first argument position in the action tier because it is the instigator of the result "dead". The two A-marked arguments are ordered as [joek6 "MEDICINE"] ${ }_{A}^{\alpha}$, [nei5 "YOU"] ${ }_{A}^{\beta}$ according to the thematic hierarchy. The first argument is linked to the external argument or subject whereas the second argument is linked to the object. The Cantonese sentence would have the same syntactic mapping as the case in Mandarin Chinese because of their identical conceptual structures.

The third type of resultative construction is a marked construction in Mandarin Chinese. The sentence “張三 追-累-了李四 Zhāngsān zhuī-lèi-le Lǐsì” (John chase-tired-ASP Lee) has been discussed in Her's (2006) paper, which claims that the sentence has three possible readings.

\section{(13) 張三 追-累-了 李四 Zhāngsān zhuī-lèi-le Lìsì \\ John chase-tired-ASP Lee}

Interpretation (i) John chased Lee and Lee got tired.

Interpretation (ii) John chased Lee and John got tired.

Interpretation (iii) Lee chased John and (Lee) got tired.

However, the second interpretation is not readily accepted by native speakers. In what follows, I am going to (i) prove my point above by looking at its conceptual structure and (ii) provide an explanation for the possibility of the third interpretation. Let us start by looking at the first 
interpretation.

Interpretation (i): John chased Lee and Lee got tired.

Interpretation (i) can be rephrased as "John made Lee tired by chasing him (Lee)".

(14) Conceptual structure of interpretation (i):

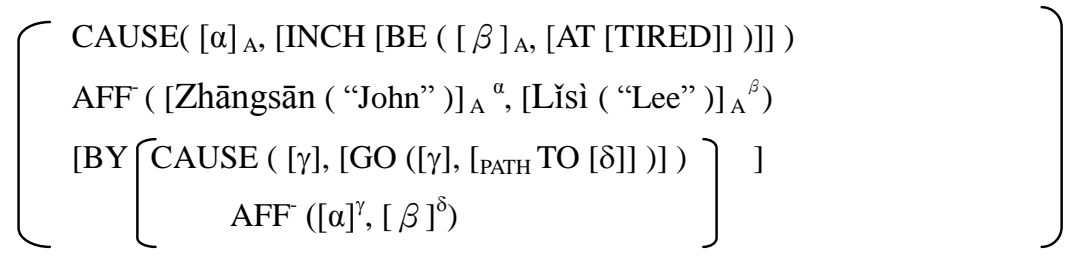

The first line, i.e. the thematic tier, denotes that an individual $[\alpha]$ is causing (i.e. CAUSE) an internal change (i.e. "INCH") on another individual $[\beta]$ to be in a state of being tired (i.e. [BE...AT [TIRED]]). The instigator of the above causative action, which is found in the first position of the action tier is "[Zhāngsān ("John")]", whereas the patient of the CAUSE action, which is denoted in the second position of the action tier, is [Lǐsì ("Lee")]. The "chasing" action is expressed by using the functions "GO" and "PATH", since "chasing" involves $A$ going along the path B takes and trying to catch B. The two A-marked arguments are ordered as [Zhāngsān ("John")], [Lisì ("Lee")]. The ACTOR, which is the first argument in the action tier, is mapped to the external argument or subject, whereas the PATIENT, which is the second argument in the action tier, is mapped to the object.

* Interpretation (ii): John chased Lee and John got tired.

The corresponding paraphrase of the intended interpretation of this sentence is "John got tired by chasing Lee." However, this interpretation is not readily accepted by native speakers of Mandarin Chinese. This can be explained by considering the conceptual structure of the interpretation. First, since there is no "external" causer involved in the internal change (INCH) of Zhāngsān ("John") being tired, the thematic tier only states that there is an individual $[\alpha]$, which is co-indexed with [Zhāngsān (“John”)], undergoes an internal change of being tired. Accordingly, there is only a single A-marked argument (i.e. [Zhāngsān ("John")] ${ }_{\mathrm{A}}$ ) in the action tier ready for mapping. According to the mapping described above, the A-marked arguments are

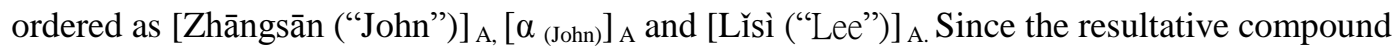
is a transitive verb, only [Zhāngsān ("John") $]_{A}$ and $\left[\alpha_{(J o h n)}\right]_{A}^{\gamma}$ will be mapped in the syntax. The conceptual structure of the intended interpretation and the mapping result shows the intended interpretation, i.e. "John chased Lee and John got tired." cannot be obtained from the sentence “張三 追-累-了 李四 Zhāngsān zhuī-lèi-le Lǐsì”.

(15) Conceptual structure of interpretation (ii):

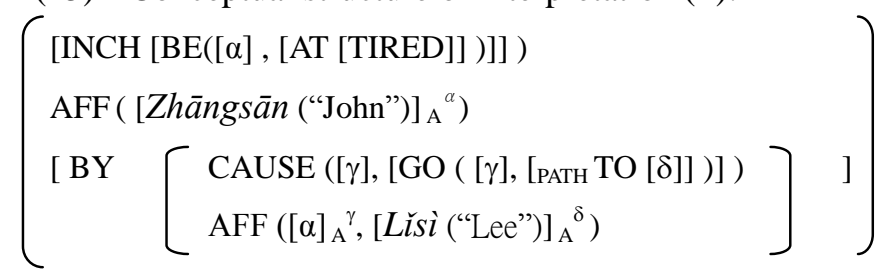


Interpretation (iii): Lee chased John and (Lee) got tired.

Interpretation (iii) can be rephrased as "Lee got tired by chasing John."

(16) Conceptual structure of interpretation (iii):

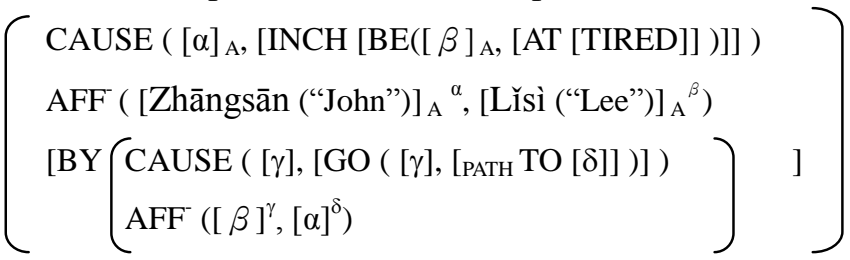

In this case, [Zhāngsān ("John")] is still the instigator of the action which causes someone tired, and thus is put in the first position of the action tier. The ACTOR [Zhāngsān ("John")] is linked to the external argument or subject whereas the PATIENT [Lǐsì ("Lee")] is linked to the object. The difference between the conceptual structure in (16) and that in (15) lies in the "BY" subpart or the superordinate adjunct. The action tier in the superordinate adjunct of the conceptual structure in (16) is "AFF" ([ $\beta$ ("Lee") $\left.]^{\gamma},[\alpha \text { ("John") }]^{\delta}\right)$ ", while the action tier in the superordinate adjunct of the conceptual structure in (14) is "AFF" ([ $\alpha$ ("John") $\left.]^{\gamma},[\beta \text { ("Lee") }]^{\delta}\right)$ ". The analysis above demonstrates how grammatical function and argument role mapping of Mandarin resultative constructions, including the marked structure discussed above can be handled naturally by Jackendoff's (1990) conceptual semantics approach. In what follows, I am going to demonstrate the mapping of Cantonese resultative construction in the conceptual semantics approach.

\section{Section 4 Mapping of Cantonese Resultatives with Verb-Copying Construction}

The syntactic structure of the resultative sentences in Cantonese resembles that of Mandarin Chinese resultative constructions. However, one major difference is that certain causing verbs or main verbs are not adjacent to the means verbs or resulting predicates. Instead, the main verbs or the causing verbs are separated from the resulting predicates and the resultative sentences are only licensed in verb-copying constructions, for example, the proposition "John chased Lee and made Lee tired." can only be expressed in a verb-copying construction like (17):

$$
\begin{aligned}
& \text { (17) 張 三 追 李四追- 到好 攰。 } \\
& \text { Zoeng3saam3 zeoi1 Lei5sei3 zeoi1 dou3 hou2 gui6 } \\
& \text { John chased Lee chased-ASP very tired } \\
& \text { "John chased Lee to an extent that Lee got tired." }
\end{aligned}
$$

Unlike the corresponding resultative sentence in Mandarin Chinese, there is only one acceptable interpretation for the Cantonese sentence, i.e. John chased Lee to an extent that Lee got tired. Moreover, there is one important point to note about this type of Cantonese resultative construction. Since the above resultative sentence is a verb-copying construction, there are semantic and syntactic properties that are not found in resultative compounds. According to 
Fang and Sells's (1997) study on verb-copying constructions in Chinese, verb-copying constructions (VCC) are considered as a type of construction in which VPs are co-ordinated. The paper argues that a VCC is "a double or multiple-headed coordinated VP, with each VP as a co-head" (Fang and Sells, 1997). The syntactic relation of a VCC is shown in (18):

$$
\begin{array}{rlr}
(18) \mathrm{VP}(\mathrm{VCC}) \rightarrow & \mathrm{VP} & \mathrm{VP}+ \\
& \uparrow \in \downarrow & \uparrow \in \downarrow \\
& \uparrow=\downarrow &
\end{array}
$$

It is also proposed that the first VP is the head of the construction and it is in a subsumption relation to all other VPs, in other words, the syntactic information of every VP under the VCC construction is subsumed by the first VP head (Zaenen and Kaplan 2002). Semantically, the first VP head is considered more general than the following VP(s) (Fang and Sells, 1997). It is shown in Fang and Sells's (1997) paper that the first VP "serves pragmatically as the secondary topic" while the co-headed VPs, usually post-verbal adjuncts, "serves as the comment to the first VP" and are considered more specific.

Given the properties of VCCs discussed by Fang and Sells (1997), we shall now consider the conceptual structure of Cantonese resultative sentences which appear as verb-copying constructions.

(19) Conceptual structure of (17):

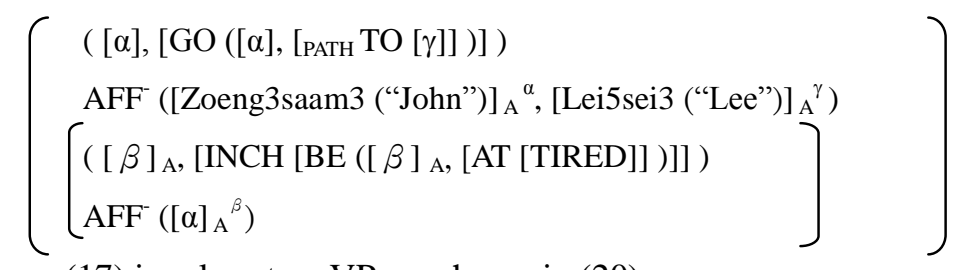

Sentence (17) involves two VPs as shown in (20)

$$
\begin{aligned}
& \mathrm{VP}(\mathrm{VCC}) \rightarrow \quad \mathrm{VP} \\
& \uparrow \in \downarrow \\
& \text { 張 三 追 李四 } \\
& \text { Zoeng3saam3 zeoi1 Lei5sei3 } \\
& \text { John chased Lee } \\
& \text { "John chased Lee" }
\end{aligned}
$$

$$
\begin{gathered}
\mathrm{VP}+. \\
\uparrow \in \downarrow \\
\text { 追- 到 好 攰 } \\
\text { zeoi1-dou3 hou2 gui6 } \\
\text { chase-ASP very tired } \\
\text { “(John) got (very) tired.” }
\end{gathered}
$$

Since the first VP is considered semantically more general, it is represented in the first two lines, which represent the main clause of the conceptual structure. The first line, i.e. the thematic tier, denotes a chasing action in which [ $\alpha$ ] (i.e. "John") GOes along the PATH [ $\beta$ ] (i.e. Lee) takes. The embedded conceptual structure represents the co-headed VP, which states that an individual $[\beta]$ which is co-indexed with $[\alpha]$ (i.e. "John") undergoes an internal change of being tired Again, since the main structure represents the more general information, it seems to be a more suitable starting place for mapping. The A-marked arguments are ordered as ([Zoeng3saam3 ("John")] ${ }_{\mathrm{A}}{ }^{\alpha}$ and [Lei5sei3 ("Lee")] ${ }_{\mathrm{A}}{ }^{\gamma}$ ). The Actor [Zoeng3saam3 ("John")] ${ }_{\mathrm{A}}{ }^{\alpha}$ in the 
action tier is mapped to the external argument or subject, while the Patient [Lei5sei3 ("Lee")] ${ }_{A}^{\gamma}$ ) is mapped to the object.

It is noted that the reflective pronoun 自己 zirgei2 (self) can be added to sentence (17) which becomes:

$$
\begin{array}{llllll}
\text { (21) 張 三 } & \text { 追 } & \text { 李四追到自己 } & \text { 好 攰 } \\
\text { Zoeng3saam3 zeoi1 } & \text { Lei5sei3 zeoi1 dou3 zi6gei2 } & \text { hou2 gui6 } \\
\text { John } & \text { chased } & \text { Lee } & \text { chased-ASP self } & \text { very tired }
\end{array}
$$

"John chased Lee to an extent that John himself is very tired."

The conceptual structure in (19) can also account for the above syntactic structure. Since the two A-marked arguments have been mapped to syntax, we have to look inside the embedded conceptual structure for an additional argument ${ }^{4}$ for mapping, which is $[\alpha]_{\mathrm{A}}{ }^{\beta}$ in this case. As $[\alpha]$ ${ }_{A}^{\beta}$ is subsumed by the main conceptual structure or, in other words, $[\alpha]_{A}{ }^{\beta}$ is bound by the main conceptual structure, the reflective pronoun 自己 zi6gei2(self) is mapped to the post-verbal position of the second VP.

\section{Section 5 Conclusion}

In this paper, I have adopted Jackendoff's (1990) conceptual semantics approach to handle the syntax-semantics interface of RVCs, which has been discussed by many researchers. The conceptual structure representation of resultative sentences with the superordinate adjunct denoted by the "BY" subpart captures the semantic and syntactic properties of resultative constructions.

There are two major findings in my paper. The first one is that the application of Jackendoff's (1990) conceptual semantics approach of mapping can successfully explain why the interpretation “John chased Lee and John got tired” for the sentence “張三 追-累-了李四 Zhāngsān zhuī-lèi-le Lìsì (John chased Lee and John got tired.) " is odd if not unacceptable. The second is that the mapping of the Cantonese verb-copying construction, i.e.“張三 追 李四追 到 好攰 Zoeng3saam3 zeoi1 Lei5sei3 zeoi1 dou3 hou2 gui6 (John chased Lee to an extent that John himself is very tired.)" involves a different conceptual structure because of its special syntactic structure.

\footnotetext{
${ }^{4}$ See footnote 2.
} 


\section{References}

Alsina, Alex. 1992. On the Argument Structure of Causatives. Linguistic Inquiry, 23(4):517--555.

Alsina, Alex. 1996b. Resultatives: A Joint Operation of Semantic and Syntactic

Structures. On-line Proceedings of the First LFG Conference, ed. by Miriam Butt and Tracy Holloway King. http://www-csli.stanford.edu/publications/LFG/lfg1.html.

Bresnan, Joan (2001). Lexical Functional Syntax. Blackwell.

Dalrymple, Mary (2001). Lexical Functional Grammar. No. 42 in Syntax and

Semantics Series. New York: Academic Press.

Dowty, David. 1979. Word Meaning and Montague Grammar. Dordrecht: Reidel.

Fang, Ji and Sells, Peter. 2007. A Formal Analysis of the Verb Copy Construction in Chinese.

On-line Proceedings of the LFG07 Conference, ed. by Miriam Butt and Tracy Holloway

King. http://csli-publications.stanford.edu/

Foley, William A., Van Valin, Robert D. 1984. Functional Syntax and Universal

Grammar. Cambridge University Press.

Her, One-Soon. 2004. Argument-Function Linking in Resultatives. Concentric:

Studies in Linguistic, 30.2: 1-34

Jackendoff, Ray. 1990. Semantics Structures. Cambridge, Mass.: MIT Press.

Li, Yafei. 1995. The Thematic Hierarchy and Causativity. Natural Language and Linguistic Theories 13:255-82.

Li, YaFei. 1999. Cross-componential Causativity. Natural Language and Linguistic Theory 27:455-497.

Simpson, Jane. 1983. Resultatives. Papers in Lexical-Functional Grammar, ed. by Lori Levin, Malka Rappaport, and Annie Zaenen, 143-57. Bloomington, IN: Indiana University Linguistics Club.

Yuzhi Shi. 1999. The Formation of the Resultative Construction and Its Effects on the Establishment of Modern Chinese Grammar. PhD dissertation submitted to the Department of Asian Languages of Stanford University.

Zaenen, Annie and Ronald M. Kaplan, 2002. Subsumption and Equality: German Partial Fronting in LFG. In Proceedings of the LFG02 Conference. M. Butt and T.H.King (eds.), CSLI Publications, Stanford, CA. 